\title{
Development and Evaluation of Polymer-bound Glibenclamide Oral Thin Film
}

\author{
Raghavendra $\mathrm{HL}^{1 *}$ and Prem Kumar $\mathbf{G}^{2}$
}

${ }^{1}$ School of Medicine, Wollega University, Nekemte, Ethiopia

${ }^{2}$ Department of Toxicology, Bioneeds India Private Limited, Bangalore, Karnataka, India

\begin{abstract}
Glibenclamide (GLB) is a second-generation sulfonylurea oral hypoglycemic agent used in the treatment of noninsulin dependent diabetes mellitus. The use of this drug is limited due to its poor dissolution and pharmacokinetic profile. In order to nullify these drawbacks, GLB oral thin films were prepared and evaluated to study the influence of preparatory conditions on the physicochemical properties by using Scanning Electron Microscopy (SEM), Fourier Transform Infra-red Spectroscopy (FTIR) and Differential Scanning Calorimetric (DSC). The surface pH of the GLB thin film was found to be in the range of $6.50 \pm 0.10$ and it is non-irritant to mucosal lining of the oral cavity. The results of the SEM analysis showed uniform surface morphology with homogenous distribution of GLB pure drug in PVP matrix. The in vitro drug release profile at pH 5.0 and 7.5 revealed sustained release patterns for a period of 8 $\mathrm{h}$. The GLB oral thin film showed an enhanced in vivo insulin release profiles as compared to pure GLB drug. Thus, the results of the present study revealed that, the prepared GLB oral thin film can be used as alternative strategy to deliver glibenclamide for diabetes mellitus as it showed a significant role in increasing in vitro dissolution and in vivo insulin release profiles.
\end{abstract}

Keywords: Sulfonylurea; Thin films; Drug release; Fourier transform infra-red spectroscopy (FTIR); Insulin release; Scanning electron microscopy (SEM); Differential scanning calorimetric (DSC)

\section{Introduction}

Glibenclamide (GLB) is a long-acting oral anti hyperglycemic agent used in the treatment of type II diabetes (noninsulin-dependent diabetes), closely related to sulfa drugs [1]. GLB acts through stimulating the insulin release from pancreatic $\beta$-cells by binding highaffinity receptors that are present in the K/ATP channels in $\beta$-cells of plasma membranes and it also increases the sensitivity of peripheral tissue to insulin [2]. Being a class II drug (it has high permeability and poor water solubility), the rate of drug dissolution is most certainly the principal limitation to its oral absorption $[3,4]$. The poor water solubility of GLB is liable for its poor dissolution rate, which ultimately leads to variable absorption of GLB [5]. The GLB showed to have a low oral bioavailability (40-45\%), short biological half-life (3-5 h), and undergoes oxidative hepatic first-pass metabolism to yield metabolites having no hypoglycemic activity [6]. All these factors contributed to glucose variability and other gastric side effects viz., nausea, vomiting, anorexia and increased appetite [6,7].

In order to reduce the dosing frequency, improve patient compliance and drug dissolution or bioavailability of GLB, several strategies have been used by the researchers, such as micronization [8], co-precipitation [3], molecular dispersion [9], modification of crystal habits of drug substances $[10,11]$, salt selection and amorphization of the compound [10,11], polymorphism [12], use of surfactants [13], glass formation [14], oil-in-water emulsion [15], freeze-drying [16] etc. The oral thin films prepared by solvent casting technique is emerged as one of the promising technique to circumvent high hepatic first-pass metabolism and harsh degradation of gastrointestinal environment $[16,17]$ and at the same time helped to improve oral bioavailability and therapeutic effect to augment patient compliance.

Various synthetic and natural polymers are available for the preparation of thin films and are the backbone of thin film formulations. The polymers will be used either alone or in combination with other polymers to achieve the desired film properties of interest [18]. Over the years, the use of muco-adhesive polymers (methylcellulose, petrolatum, sodium alginate, cyanoacrylates, guar gum, care gum, pectin, gelatin, lectins, fimbrin, retene, tragacanth, polyacrylic acid, polyethylene glycol etc.) for the development of new pharmaceutical formulations have been employed to overcome conventional drugs drawbacks [19-22]. The employed polymers should be non-toxic, non-irritant, and non-immunogenic in nature to prepare oral thin films [18]. By keeping the above facts, the study was designed to prepare GLB oral thin films using PVP as a polymer matrix and to evaluate their physic-chemical properties by employing Scanning Electron Microscopy (SEM), Fourier Transform Infra-red Spectroscopy (FTIR) and Differential Scanning Calorimetric (DSC) processes. The thin films were also evaluated for in vitro drug release and in vivo insulin release process.

\section{Materials and Methods}

\section{Materials}

Glibenclamide (Assay purity $\geq 99 \%$ ), Polyvinylpyrrolidone $(\mathrm{Mw}=13,00,000)$ and Dialysis tubing cellulose membrane were obtained from Sigma-Aldrich, Germany. Methanol, Chloroform, Monobasic sodium phosphate $\left(\mathrm{NaH}_{2} \mathrm{PO}_{4}\right)$ and dibasic sodium phosphate $\left(\mathrm{Na}_{2} \mathrm{HPO}_{4}\right)$ were procured from Emplura, Merck Specialties Private Limited. Insulin was estimated using a Radioimmunoassay kit (RIAK1) supplied by Bhabha Atomic Research Centre/Board of Radiation and Isotope Technology (BARC/BRIT; Mumbai, India).

*Corresponding author: Raghavendra HL, School of Medicine, P.O. Box 395, Wollega University, Nekemte, Ethiopia, Tel: +251 922253091; E-mail: raghu.biogem@gmail.com (or) id: drpremkamal@gmail.com

Received November 24, 2016; Accepted December 19, 2016; Published January 03, 2017

Citation: Raghavendra HL, Kumar GP (2017) Development and Evaluation of Polymer-bound Glibenclamide Oral Thin Film. J Bioequiv Availab 9: 324-330. doi: 10.4172/jbb.1000319

Copyright: (c) 2017 Raghavendra HL, et al. This is an open-access article distributed under the terms of the Creative Commons Attribution License, which permits unrestricted use, distribution, and reproduction in any medium, provided the original author and source are credited. 
Citation: Raghavendra HL, Kumar GP (2017) Development and Evaluation of Polymer-bound Glibenclamide Oral Thin Film. J Bioequiv Availab 9: 324-330. doi: 10.4172/jbb.1000319

\section{Preparation of GLB thin film}

The GLB thin films were prepared using a solvent casting technique [23] by using PVP. PVP solution (10\% w/v) was prepared by dissolving it in methanol by stirring it continuously for about $10 \mathrm{~min}$ to obtain a clear homogeneous solution and GLB solution ( $8 \% \mathrm{w} / \mathrm{v})$ were prepared in a solvent mixture of chloroform: methanol (1:3) separately. The PVP solution and solvent mixture were mixed together in the ratio of 1:3 and stirred for about half an hour. Furthermore, the mixture was poured into a plastic mould, safely covered and kept overnight at room temperature for solvent evaporation. Finally, prepared GLB oral thin films were used to evaluate their physic-chemical properties, in vitro drug release and in vivo insulin release.

\section{Characterization of GLB oral thin film}

Scanning Electron Microscopy (SEM): The surface morphology of the GLB pure drug, GLB thin films and PVP thin films were characterized by using Field Emission Scanning Electron Microscope (FESEM, FEI Sirion) at operating voltage of 5-30 KV and all the images were recorded at working distance of 8-10 $\mathrm{mm}$ [23].

FTIR analysis: The procedure involving sample preparation and spectral recordings were carried out by using previously described method of Stuart [24]. IR spectra of GLB pure drug, PVP thin film and GLB thin film were recorded using FTIR Nicolet 6700 (Thermo Fisher Scientific, Madisson, WI, USA) operated by Omnic software 8.1. The spectra were obtained by Attenuated total reflectance (ATR) method using smart orbit diamond ATR. In Brief, each thin film was placed individually on the sample plate of the smart orbit and screwed lightly to record IR spectra in ATR mode.

Differential Scanning Calorimeter (DSC): The differential scanning calorimeter (Mettler-Toledo DSC 821e, Switzerland) analysis of thin films were carried out with initial and final temperatures at $0^{\circ} \mathrm{C}$ and $300^{\circ} \mathrm{C}$ respectively allowing rise in temperature to the tune of $10^{\circ} \mathrm{C} / \mathrm{min}$ in argon atmosphere and DSC curves were evaluated with STARe software (Mettler-Toledo) [23].

Surface pH: The surface $\mathrm{pH}$ of GLB thin films were measured by using combined $\mathrm{pH}$ electrode and films were moistened with mille-Qwater and $\mathrm{pH}$ was measured at the inter-phase of water and film [25].

Measurement of oral thin film thickness: The thickness of oral thin films was measured in triplicate by using calibrated digital Verniar calipers (Mitutoyo 550-203-10, Mitutoyo, Japan) and mean value of thickness was recorded [26].

Folding endurance: The folding endurance capability of the thin films was determined by repeatedly folding the film $(4 \mathrm{~cm} \times 4 \mathrm{~cm})$ at the same point until a breaking point was arrived. The total number of times, the film could be folded at the same point without breaking was considered as the folding endurance value. All the tests were performed for four times and mean of the values was reported [27].

Swelling percentage (\% S): The swelling index of the films was conducted in simulated salivary fluid at $\mathrm{pH}$ 6.75. Briefly, the films (surface area $4 \mathrm{~cm}^{2}$ ) were weighed and transferred onto a stainlesssteel mesh (sieve size approximately $800 \mu \mathrm{m}$ ). This arrangement was later sunken to $50 \mathrm{ml}$ of simulated salivary medium. At definite time interval (30 s), the stainless-steel mesh was removed; excess moisture was separated carefully with filter paper and reweighed. Increase in weight of the film was determined at every time interval until a constant weight was subsequently found. The swelling percentage was calculated by using the following formula $[28,29]$.

\section{$\left(\mathrm{X}_{\mathrm{t}}-\mathrm{X}_{0}\right)$}

$\% \mathrm{~S}=-\times 100$

$\mathrm{X}_{0}$

Where, \% S: Swelling percentage, $\mathrm{X}_{\mathrm{t}}$ : The weight of swollen film after time $t$, and $X_{0}$ : Weight of film at zero time.

In vitro disintegration time: The in vitro disintegration time was measured by following the monograph of United States Pharmacopeia (USP) using disintegration test apparatus (LABINDIA, DS8000) [30].

Solubility studies: The drug concentration of $1 \mathrm{mg} / \mathrm{ml}$ GLB pure drug and GLB thin film was taken in a beaker containing Phosphate Buffer Solution (PBS) (pH 5.0 and 7.5) and were incubated at $37^{\circ} \mathrm{C} \pm$ $0.1^{\circ} \mathrm{C}$ under dynamic conditions and amount of drug dissolved was noted visually [31]

\section{Estimation of drug content}

A sample of $4 \mathrm{~cm}^{2}$ square of thin film was dissolved in $10 \mathrm{ml}$ methanol and shaken it for $5 \mathrm{~min}$ to extract drug from the formulation. Finally, the solution was filtered through Whatman filter paper and the drug content was analysed spectrophotometrically at $228 \mathrm{~nm}$ using methanol as blank. The mean and standard deviation of drug content of three randomly selected films were calculated [32].

In vitro drug release: The in vitro drug release studies of thin films were performed using USP Apparatus-I at $50 \mathrm{rpm}$ and $900 \mathrm{ml}$ of PBS (pH 5.0 and 7.5 ) at $37^{\circ} \mathrm{C} \pm 0.5^{\circ} \mathrm{C}$. The $10 \mathrm{mg}$ (concentration 1 $\mathrm{mg} / \mathrm{ml}$ ) of GLB pure drug, GLB commercial drug and GLB thin film were separately placed in dialysis tube and immersed in PBS at pH 5.0 and 7.5. At pre-determined time intervals $(0,5,15,30 \mathrm{~min}, 1,2,3,4$, 6 and $8 \mathrm{~h}$ ), an aliquot of $4 \mathrm{ml}$ of the released media was withdrawn for determining the in vitro drug release. The concentration of the drug in release media was estimated by UV spectroscopy Evolution 300 (Thermo Fisher Scientific, Madisson, WI, USA) operated by Vision Pro software at $228 \mathrm{~nm}$ and the regression equation of standard curve developed in the same media. The dissolution medium was replaced with fresh buffer $(4 \mathrm{ml})$ to maintain constant total volume at every time interval $[33,34]$.

In vivo insulin release assay: Ten to twelve week old healthy Wister rats of either sex weighing around $220 \mathrm{~g} \pm 20 \mathrm{~g}$ were procured from the Laboratory Animal Facility, Department of Pharmacology, College of Pharmacy, Bagalkot, Karnataka, India. All animals were maintained as per the protocol outlined in the publication of the Committee for the Purpose of Control and Supervision of Experiments on Animals (CPCSEA) [35]. The experimental protocol was approved by the Institutional Animal Ethics Committee (IAEC) bearing approval No. HSKCOP/IAEC/2014/RP-14. The animals were acclimatized at temperature of $22^{\circ} \mathrm{C} \pm 3{ }^{\circ} \mathrm{C}$ and relative humidity of $50-60 \%$ under 12 $\mathrm{h} / 12 \mathrm{~h}$ light/dark conditions for 5 days before the start of experiment. During experimentation all the animals were provided with a standard pellet diet (Provimi Animal Nutrition India Pvt. Ltd., Bangalore, Karnataka, India), and water ad libitum and same animals were fasted overnight (16-18 h) before the dose administration and water were made available ad libitum. The total animals $(n=18)$ were arbitrarily distributed into three groups [Group I: Normal control, Group II: GLB pure drug, Group III: GLB thin film). The both formulations were administered orally using oral gavages at a calculated dose of GLB (100 $\mathrm{mg} / \mathrm{kg}$ body weight). The blood sample $(\approx 0.3 \mathrm{ml}$ ) were collected from the retro-orbital plexus under isoflurane anaesthesia at predetermined intervals of $0,1,2,4,8,12$ and $18 \mathrm{~h}$ into the micro centrifuge tubes 
Citation: Raghavendra HL, Kumar GP (2017) Development and Evaluation of Polymer-bound Glibenclamide Oral Thin Film. J Bioequiv Availab 9: 324-330. doi: 10.4172/jbb.1000319

containing K2EDTA $(2 \mathrm{mg} / \mathrm{mL})$, as an anticoagulant. The blood samples were centrifuged at $5000 \mathrm{rpm}$ for $10 \mathrm{~min}$ at $4^{\circ} \mathrm{C}$ to separate plasma from erythrocytes and stored at $80^{\circ} \mathrm{C}$ until assayed by RIA with rat insulin standards (RIAK-1, BARC/ BRIT; Mumbai, India).

Statistical analysis: The data of in vitro release and in vivo insulin release studies were subjected to Student's unpaired' $t$ ' test. The $P$ value $<0.05$ was considered as significant. Mean values and standard error of mean were calculated and all the values were expressed as Mean \pm SEM (Graph Pad Prism 5 Software).

\section{Results and Discussion}

\section{Oral thin films characterization}

Visual examination of thin film: The visual observations of the thin films were showed that, there was no difference among the PVP and GLB thin film with respect to colour, flexibility, surface uniformity and transparency (Figure 1). The prepared thin films were elegant enough, transparent, flexible, smooth and homogeneous [36].

SEM analysis: The surface morphology of the GLB pure drug (Figures $2 \mathrm{a}$ and $2 \mathrm{~b}$ ) and GLB thin film (Figures $2 \mathrm{c}$ and $2 \mathrm{~d}$ ) with low and high magnification respectively were represented in Figure 2 . The SEM image of GLB pure drug showed irregular particle size of diameters in the range of $15-45 \mu \mathrm{m}$ (Image J software, provided by National Institutes of Health, USA) [37]. This irregular microcrystalline structure of the GLB pure drug might be one of the reasons to illustrate its poor pharmacokinetic profile. SEM image of GLB thin film showed uniform surface morphology with homogenous distribution of GLB pure drug in PVP matrix. The SEM results of the study, helped to understand PVP mechanism to formulate smaller drug particles with increased surface area and wet-ability; which in turn advantageous to enhance the dissolution rate of a poorly soluble drug [38].

FTIR analysis: The FTIR analysis was conducted to evaluate the physicochemical compatibility of GLB and PVP as a drug delivery system (Figure 3). The GLB pure drug (Figure 3a) showed characteristic amide peaks at $3362.54,3317.59$ and $1712.86 \mathrm{~cm}^{-1}$ (N-H stretching), urea carbonyl stretching (urea $\mathrm{N}-\mathrm{H}$ stretching) vibrations at 1615.25 and $1276.75 \mathrm{~cm}^{-1}, \mathrm{SO}_{2}$ stretching vibrations at 1340.15 and $1156.07 \mathrm{~cm}^{-1}$, C-H aliphatic stretching vibrations at $2933.48 \mathrm{~cm}^{-1}$, O-H stretching vibrations at $2847.67 \mathrm{~cm}^{-1}, \mathrm{~N}-\mathrm{O}$ stretching vibrations at 1518.35 and $1449.20 \mathrm{~cm}^{-1}$, C-N stretching vibrations at $1243.58 \mathrm{~cm}^{-1}$ and $\mathrm{C}-\mathrm{O}$ stretching vibrations at $1010.99 \mathrm{~cm}^{-1}$ [38-40]. The presence of various prominent functional groups in PVP thin film (Figure $3 \mathrm{~b}$ ) was observed and the broad absorption band at $3398.14 \mathrm{~cm}^{-1}$ was due to $\mathrm{O}-\mathrm{H}$ stretching vibrations of hydrogen-bonded water. The absorption peak at $2950.87,1372.25 \mathrm{~cm}^{-1}$ may be due to the $\mathrm{C}-\mathrm{H}$ stretching vibration in PVP [41]. A peak at $1643.27 \mathrm{~cm}^{-1}$ was assigned to the stretching vibration of the $\mathrm{C}=\mathrm{O}$. Other imperative peaks at $1287.50 \mathrm{~cm}^{-1}$ and the doublet at $1438.03,1422.04 \mathrm{~cm}^{-1}$ were assigned to the $\mathrm{C}-\mathrm{N}$ stretching vibrations and the attachment of $\mathrm{CH}_{2}$ groups in the pyrrole ring of PVP $[42,43]$. The spectra of optimized GLB thin film (Figure 3c) exhibited all the principle peaks present in the PVP thin film. This unchanged spectrum of PVP and GLB thin film showed the non-interactive nature of polymer and drug and, this non-interactive nature may be due to the encapsulation or masking nature of PVP with GLB pure drug.

Differential Scanning Calorimeter (DSC): The DSC analysis was performed to assess the thermal behaviour of the GLB pure drug, PVP thin film and GLB thin film as a drug delivery system. The DSC thermo grams of the GLB pure drug, PVP thin film and GLB thin film were shown in Figure 4. The DSC thermo grams of GLB pure drug indicated the melting onset, peak and end set at 173.84, 177.38 and $181.32^{\circ} \mathrm{C}$ respectively, which in turn showed the corresponding melting behaviour of the stable anhydrous form of crystalline GLB [44,45]. The DSC thermo grams of PVP thin film indicated melting onset, peak and end set at $146.22,147.85$ and $156.05^{\circ} \mathrm{C}$ respectively [46-48]. However, the DSC of GLB thin film indicated the GLB and PVP endothermic peaks at 172.80 and $122.61^{\circ} \mathrm{C}$ respectively, with slight decrease in the melting point (Figure 4). The observed slight decline in melting point and intensity of GLB endothermic peak of DSC thermo grams of thin film formulation might be partially attributed to the transformation of crystalline to amorphous drug or to the dissolution of drug in the carrier system at the temperatures below its melting point $[49,50]$. The broad endothermic peak ranging from $96.37-143.81^{\circ} \mathrm{C}$ might again be attributed due to the presence of residual moisture in PVP [51]. Finally, the observed peak of GLB in the DSC thermo grams of prepared thin film (GLB-PVP) was due to non-interactive nature of GLB pure drug and PVP polymer.

Evaluation of GLB containing-PVP oral thin films: The surface $\mathrm{pH}$ of GLB oral thin film was determined in order to examine the effect of $\mathrm{pH}$ on oral mucosa and surface $\mathrm{pH}$ of the GLB thin film was found to be in the range of $6.50 \pm 0.10$, which was almost neutral and nonirritant to the mucosal lining of the oral cavity [25]. As the thickness of film was directly concerned with drug content uniformity, then it was necessary to establish uniformity in the thickness of the film. The prepared films were evaluated for thickness using digital Vernier calipers and the mean value was found to be $0.136 \mathrm{~mm} \pm 0.019 \mathrm{~mm}$, which indicates the uniform surface nature of the prepared films [26]. The folding endurance determination will help to determine the mechanical strength like brittleness; flexibility etc. of the films and the increased folding endurance was directly proportional to its mechanical strength. The folding endurance of the drug loaded thin films was estimated and was found to be $460.75 \pm 1.013$, which indicates its acceptability for mechanical strength as necessitated in a drug delivery system. The penetrations of solvents into the polymer matrix led to increased weight of the films and facilitated diffusion of drug molecules from the thin film matrix to external environment [52]. The mean swelling percentage was determined and found to be $25.73 \%$. The observed results entailed that, the absorption of water by the films was considerable for the drug release. Disintegration time will give an indication about the onset of action, which was desirable for oral thin films [53]. The calculated mean time for the film to disintegrate into complete fine particles was found to be $0.30 \mathrm{~min} \pm 0.16 \mathrm{~min}$ and to completely disappear into the solution was found to be $1.00 \mathrm{~min}$ $\pm 0.21 \mathrm{~min}$. These values indicated that, the films had optimum disintegration time.

In vitro drug release: The in vitro dissolution profiles of GLB and GLB thin film at pH 5.0 and 7.5 were illustrated in Figure 5. The dissolution rate of GLB thin film at $1 \mathrm{~h}$ (@ pH 5.0 and 7.5) were 66\% and $69 \%$; whereas, the GLB pure drug were $41 \%$ and $40 \%$ respectively. Additionally, it was noticed that a maximum percent release of GLB at pH 5.0 and 7.5 (@ 3 h) from the GLB thin film (76\% and $90 \%)$ and GLB pure drug $(50 \%$ and $60 \%)$ respectively. The percent drug release at $8 \mathrm{~h}$ (@ pH 5.0 and 7.5) from GLB thin film and GLB pure drug remained same till $3 \mathrm{~h}$. The obtained data of drug dissolution rate of GLB thin film was greatly influenced by the solvent cast technique. The better release profiles in the PVP oral film might be partially ascribed due to towering surface area, enhanced porosity and excellent wettability of the polymer matrix $[54,55]$. However, the release profiles assorted with pH (@ pH 5.0 and 7.5) of the release medium due to varied tortuosity and porosity of polymer matrix [56]. The drug release might have 
Citation: Raghavendra HL, Kumar GP (2017) Development and Evaluation of Polymer-bound Glibenclamide Oral Thin Film. J Bioequiv Availab 9: 324-330. doi: 10.4172/jbb.1000319

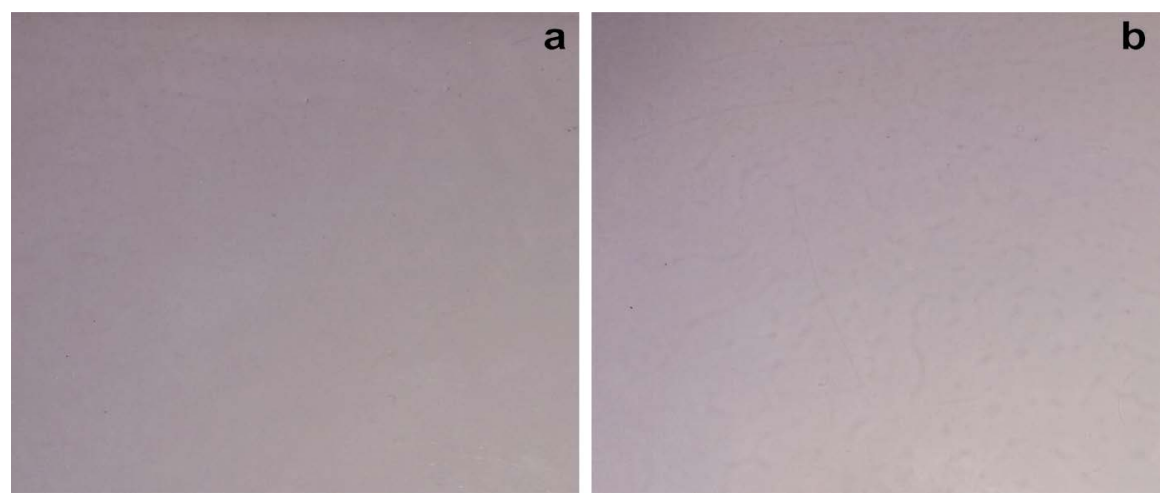

Figure 1: PVP thin film (a) and PVP-GLB thin film (b) prepared by solvent casting technique.
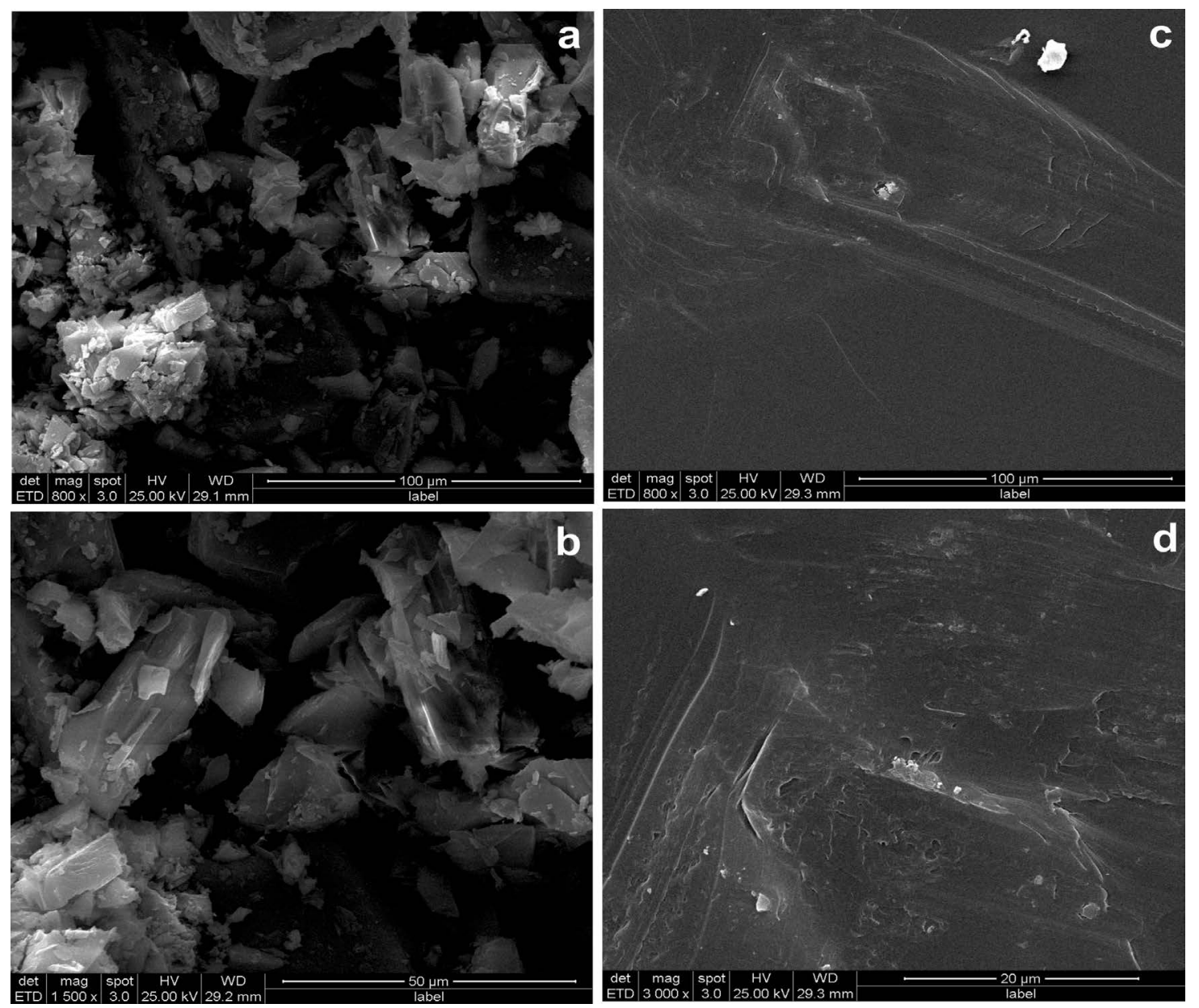

Figure 2: SEM images GLB (a \& b) and PVP-GLB thin film (c \& d) with low and high magnification.

occurred when the dissolution medium penetrated into the matrix to dissolve drug and created a channel through which diffusion occurred. The average diffusion path might have been increased with an increase in tortuosity. Furthermore, an augment in porosity helped in drug dissolution and drug release profile. On the whole, the PVP oral film exhibited better sustained drug release than GLB pure drug. This could be attributed to the less porosity and more tortuosity nature of the PVP polymer matrix as a drug delivery system $[57,58]$.
In vivo insulin release assay: Insulin resistance is a complex metabolic condition, which will affect the ability of peripheral tissues to respond to insulin. It is an important feature of metabolic syndrome and type 2 diabetes, and is a major risk factor for micro and macro vascular complications [59]. In the present study, the effect of GLB oral film on insulin release was compared with GLB pure drug (Figure 5). The estimated basal value of insulin in Group I (Normal control), Group II (GLB pure drug) and Group III (GLB thin film) was found 
Citation: Raghavendra HL, Kumar GP (2017) Development and Evaluation of Polymer-bound Glibenclamide Oral Thin Film. J Bioequiv Availab 9: 324-330. doi: 10.4172/jbb.1000319

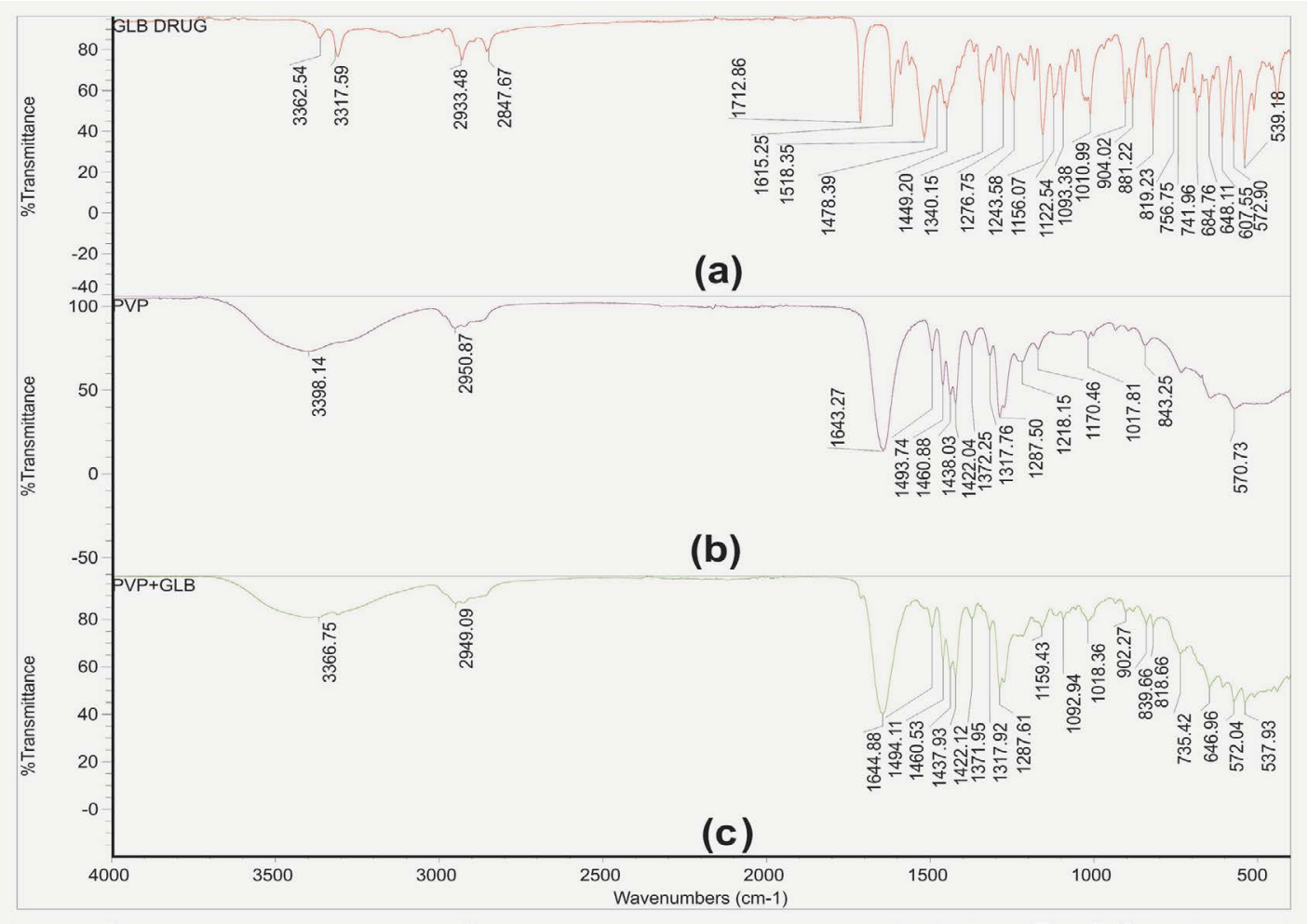

Figure 3: FTIR spectra of (a) GLB, (b) PVP thin film and (c) PVP-GLB thin film.

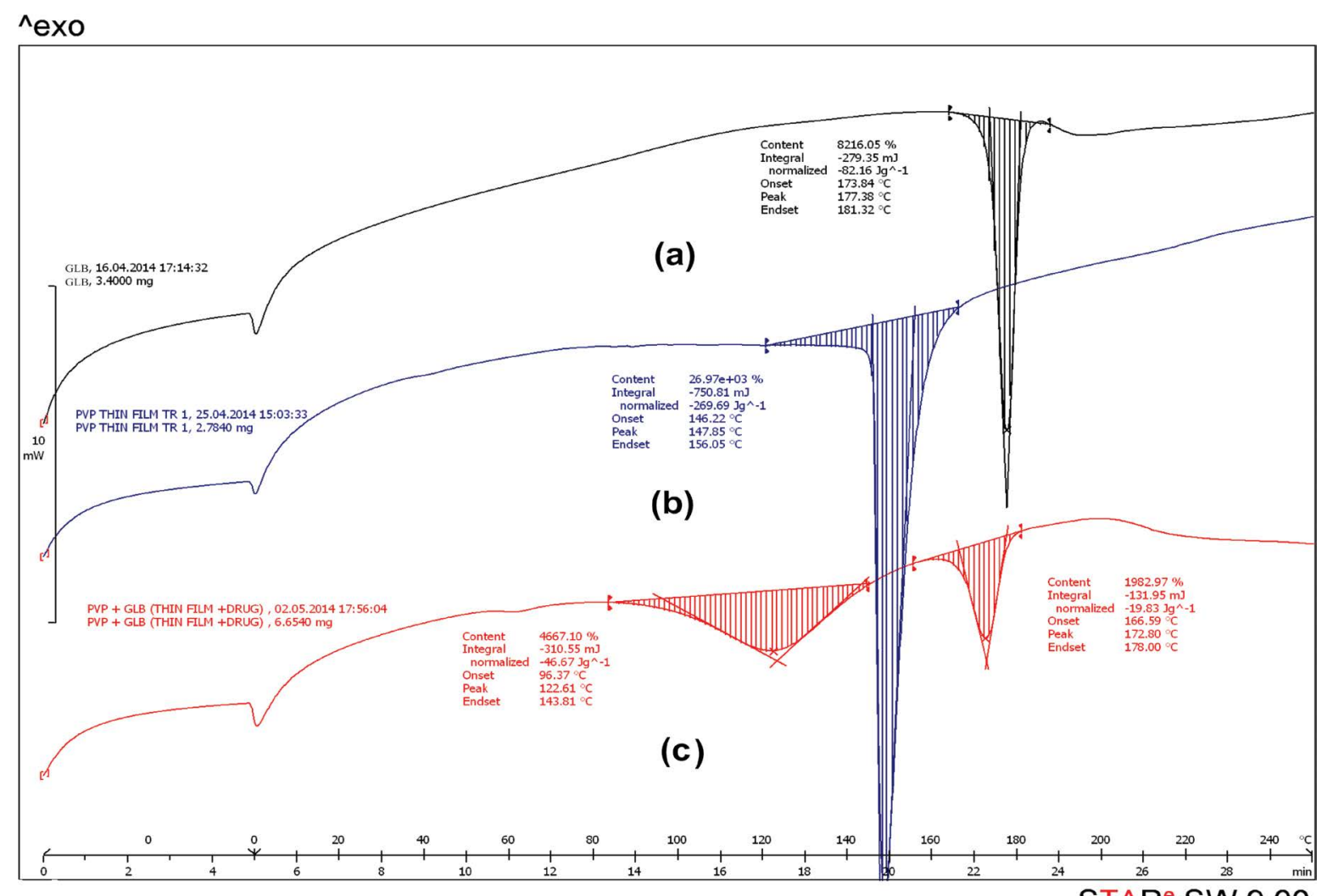

Figure 4: DSC plots of (a) GLB, (b) PVP thin film and (c) PVP-GLB thin film. 
Citation: Raghavendra HL, Kumar GP (2017) Development and Evaluation of Polymer-bound Glibenclamide Oral Thin Film. J Bioequiv Availab 9: 324-330. doi: 10.4172/jbb.1000319
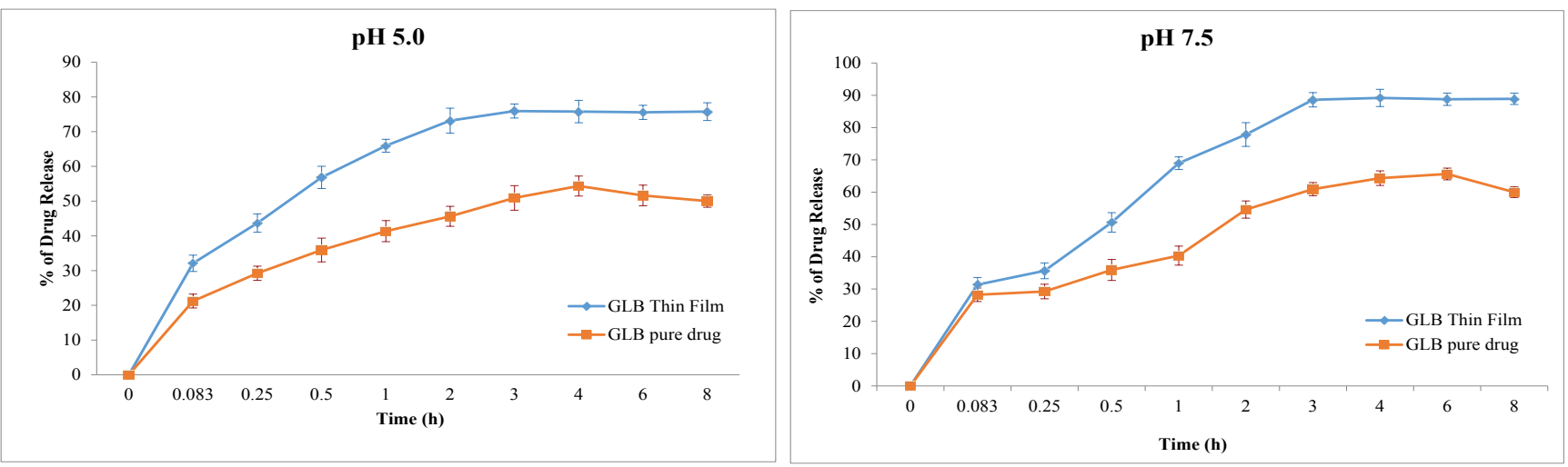

Figure 5: In vitro dissolution profiles of GLB and PVP-GLB thin film at pH 5 and 7.5 .

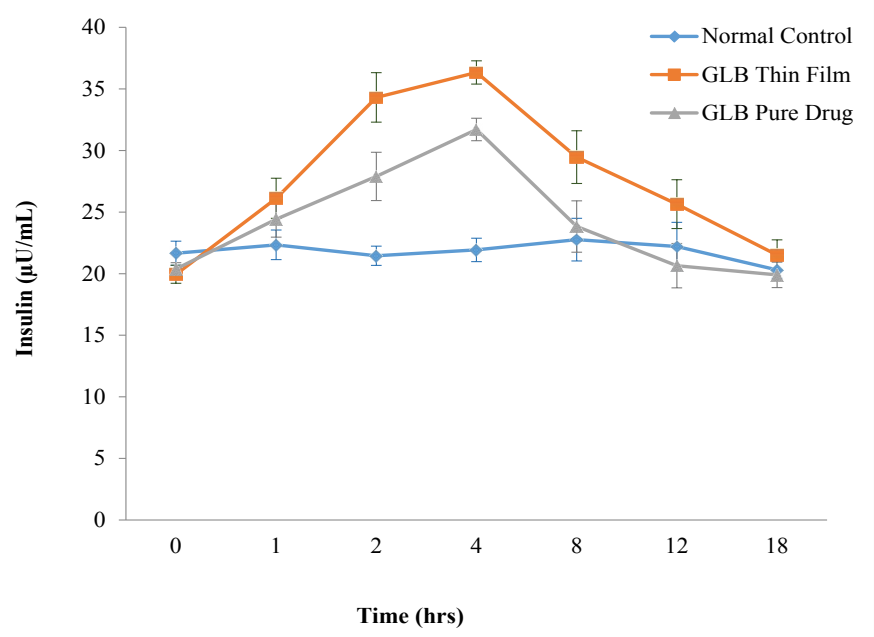

Figure 6: In vivo insulin release profile of normal control, GLB pure drug and PVP-GLB thin film.

to be $11.66 \mu \mathrm{U} / \mathrm{ml} \pm 0.023 \mu \mathrm{U} / \mathrm{ml}, 9.38 \mu \mathrm{U} / \mathrm{ml} \pm 0.23 \mu \mathrm{U} / \mathrm{ml}$ and 9.35 $\mu \mathrm{U} / \mathrm{ml} \pm 0.163 \mu \mathrm{U} / \mathrm{ml}$ respectively. The estimated insulin release was observed maximum at $4 \mathrm{hrs}$ for GLB pure drug $(21.71 \mu \mathrm{U} / \mathrm{ml} \pm 0.175$ $\mu \mathrm{U} / \mathrm{ml})$ and $\mathrm{GLB}$ thin film $(26.34 \mu \mathrm{U} / \mathrm{ml} \pm 0.216 \mu \mathrm{U} / \mathrm{ml})$. The estimated insulin release of GLB pure drug retuned to basal value $(8.90 \mu \mathrm{U} / \mathrm{ml}$ $\pm 0.372 \mu \mathrm{U} / \mathrm{ml})$; whereas of GLB thin film $(12.52 \mu \mathrm{U} / \mathrm{ml} \pm 0.216 \mu \mathrm{U} /$ $\mathrm{ml}$ ) was persistent at $18 \mathrm{~h}$ after drug administration. The results of the present study showed the enhanced insulin release properties of GLB thin film, when compared to GLB pure drug at the selected dose and route of administration (Figure 6).

\section{Conclusions}

In this research work, GLB thin film was prepared by using PVP as a polymer matrix. The preparation of GLB thin film was performed by using simple solvent casting technique, which could have been easily scaled up. The SEM analysis confirmed the uniform distribution of the drug in the film. The FTIR spectra and DSC thermo grams results indicated the absence of interaction between the GLB and PVP as a drug delivery system. GLB thin film enhanced the drug release process to a considerable extent, as confirmed by in vitro drug release study. In vivo insulin release profile of GLB oral thin film had shown superior release process against GLB pure drug. Therefore, this solvent casting technique could have been among useful alternative strategies to deliver glibenclamide for diabetes mellitus and as well as for other drugs to relieve chronic illness viz., hypertension, hypothyroidism, multiple sclerosis, Parkinson's, rheumatoid arthritis etc. Finally, solvent casting technique served as a useful simple technique to afford patients compliance by easing off drawbacks of glibenclamide.

\section{Conflict of Interest}

The author reported no declarations of conflict of interest.

\section{Acknowledgements}

Authors are thankful to the Department of Veterinary Pharmacology and Toxicology, Veterinary College, Bangalore, for providing all facilities in carrying out this study.

\section{References}

1. Shimizu T, Nathan DM, Buse JB, Davidson MB, Ferrannini E, et al. (2012) Medical management of hyperglycemia in type 2 diabetes: a consensus algorithm for the initiation and adjustment of therapy: a consensus statement of the American Diabetes Association and the European Association for the Study of Diabetes. Nihon Rinsho 70: 591-601.

2. MacDonald PE, Joseph JW, Rorsman $P(2005)$ Glucose-sensing mechanisms in pancreatic beta-cells. Philos Trans R Soc Lond B Biol Sci 360: 2211-2225.

3. Williams HD, Trevaskis NL, Charman SA, Shanker RM, Charman WN, et al (2013) Strategies to address low drug solubility in discovery and development. Pharmacol Rev 65: 315-499.

4. Dahan A, Miller JM, Amidon GL (2009) Prediction of solubility and permeability class membership: provisional BCS classification of the world's top oral drugs. AAPS J 11: 740-746.

5. Lennernäs $\mathrm{H}, \mathrm{Abrahamsson} \mathrm{B}$ (2005) The use of biopharmaceutic classification of drugs in drug discovery and development: current status and future extension. J Pharm Pharmacol 57: 273-285.

6. Kumar A, Bali V, Kumar M, Pathak K (2013) Comparative evaluation of porous versus nonporous mucoadhesive films as buccal delivery system of glibenclamide. AAPS Pharm Sci Tech 14: 1321-1332.

7. Gaudanavar PS, Bagali RS, Patil SM, Chandashkhara S (2010) Formulation and in vitro evaluation of mucoadhesive buccal films of glibenclamide. Der Pharmacia Lett 2: 382-387

8. Savjani KT, Gajjar AK, Savjani JK (2012) Drug solubility: importance and enhancement techniques. ISRN Pharm 2012: 195727.

9. Rawat N, Kumar MS, Mahadevan N (2011) Solubility: Particle size reduction is a promising approach to improve the bioavailability of lipophillic drugs. Int J Adv Pharmaceut Res 1: 8-18.

10. Leleux J, Williams RO 3rd (2014) Recent advancements in mechanical reduction methods: particulate systems. Drug Dev Ind Pharm 40: 289-300.

11. Blagden N, de Matas M, Gavan PT, York P (2007) Crystal engineering of active 
Citation: Raghavendra HL, Kumar GP (2017) Development and Evaluation of Polymer-bound Glibenclamide Oral Thin Film. J Bioequiv Availab 9: 324-330. doi: 10.4172/jbb.1000319

pharmaceutical ingredients to improve solubility and dissolution rates. Adv Drug Deliv Rev 59: 617-630.

12. Deerle D, Patel J, Yeole D, Amith P, Ashok P (2010) Particle engineering techniques to enhance dissolution of poorly water soluble drugs. Int $\mathrm{J}$ Curr Pharmaceut Res 2: 10-15.

13. Junghanns JU, Müller RH (2008) Nanocrystal technology, drug delivery and clinical applications. Int J Nanomed 3: 295-309.

14. Patterson JE, James MB, Forster AH, Lancaster RW, Butler JM, et al. (2007) Preparation of glass solutions of three poorly water soluble drugs by spray drying, melt extrusion and ball milling. Int J Pharm 336: 22-34.

15. Jones MC, Leroux JC (1999) Polymeric micelles a new generation of colloidal drug carriers. Eur J Pharm Biopharm 48: 101-111.

16. Kwon GS, Okano T (1996) Polymeric micelles as new drug carriers. Adv Drug Deliv Rev 21: 107-116.

17. Gaucher G, Dufresne MH, Sant VP, Kang N, Maysinger D, et al. (2005) Block copolymer micelles: preparation, characterization and application in drug delivery. J Control Release 109: 169-188.

18. Sandeep K, Hyeongmin K, Seon-Jeong N, Dohyun S, Kanghee J, et al. (2016) Thin films as an emerging platform for drug delivery. Asian J Pharm Sci 11: 559-574.

19. Dressman JB, Vertzoni M, Goumas K, Reppas C (2007) Estimating drug solubility in the gastrointestinal tract. Adv Drug Deliv Rev 59: 591-602.

20. Sudhakar Y, Kuotsu K, Bandyopadhyay AK (2006) Buccal bioadhesive drug delivery-a promising option for orally less efficient drugs. J Control Release 114: 15-40.

21. Smart JD, Kellaway IW, Worthington HEC (1984) An in vitro investigation of mucosa adhesive materials for use in controlled drug delivery. J Pharm Pharmacol 36: 295-299.

22. Smart JD (2005) The basics and underlying mechanisms of mucoadhesion Adv Drug Deliv Rev 57: 1556-1568.

23. Kumar GP, Phani AR, Prasad RG, Sanganal JS, Manali N, et al. (2014) Polyvinylpyrrolidone oral films of enrofloxacin: film characterization and drug release. Int J Pharm 471: 146-152.

24. Stuart B (2004) Infrared Spectroscopy: Fundamentals and Applications. John Wiley \& Sons, Inc., USA.

25. Dinge A, Nagarsenker M (2008) Formulation and Evaluation of Fast Dissolving Films for Delivery of Triclosan to the Oral Cavity. AAPS Pharm Sci Tech 9: 349-356.

26. Raju S, Sandeep RP, Anirudh KV, Deepthi A, Sreeramulu RK, et al. (2011) Flash release oral films of metoclopramide hydrochloride for pediatric use: formulation and in vitro evaluation. J Chem Pharm Res 3: 636-646.

27. Shinde AJ, Garala KC, More HN (2008) Development and characterization of transdermal therapeutics system of tramadol hydrochloride. Asian J Pharmaco 2: $265-269$.

28. Mona N, Mayank N, Vikram C (2012) Formulation and evaluation of mouth dissolving film of antipsychotic drug aripiprazole. Der Pharmacia Lett 4: 12211227.

29. Semalty A, Bhojwani M, Bhatt GK, Gupta GD, Shrivastav AK (2005) Design and evaluation of muco-adhesive buccal films of diltiazem hydrochloride. Indian J Pharm Sci 67: 548-552.

30. The United States Pharmacopoeia (2009) National Fomulary-21, Asian Ed. U S. Pharmacopoeial convention, Inc., Rockville, MD, USA, pp: 726-727.

31. Mosharraf M, Nystrom C (2003) Apparent solubility of drugs in partially crystalline systems. Drug Dev Ind Pharm 29: 603-622.

32. Roshan CC, Raju OS, Vishal VP, Laximikant RZ, Prashant BJ (2013) Design development and evaluation of oral thin films of montelukast sodium. Am J PharmTech Res 3: 387-398.

33. Sonia TA, Sharma CP (2011) Chitosan and its derivatives for drug delivery perspective. Adv Polym Sci 243: 23-54.

34. Kumar PG, Sanganal JS, Manohara C, Swamy KB, Aparna V, et al (2014) Preparation characterization and in vitro drug release studies of 6-mercaptopurine thin film. Sci Technol Arts Res J 3: 63-67.
35. CPCSEA (2003) CPCSEA guidelines for laboratory animal facility: committee for the purpose of control and supervision on experiments on animals. Indian $J$ Pharmacol 35: 257-274.

36. Sayed HA, Mahmoud ELB, Mohamed Al (2014) Design, formulation and characterization of fast dissolving films containing dextromethorphan. Dig J Nanomater Biostruct 9: 133-141.

37. Schneider CA, Rasband WS, Eliceiri KW (2012) NIH Image to Image: 25 years of image analysis. Nature Method 9: 671-675.

38. Prashant U, Jayanta KP (2012) Formulation of Fast-Release Gastroretentive Solid Dispersion of Glibenclamide with Gelucire 50/13. Trop J Pharm Res 11: 361-369.

39. Elbary AAA, Salem HF, Maher ME (2011) In vitro and in vivo Evaluation of Glibenclamide using Surface Solid Dispersion (SSD) Approach. $\mathrm{Br} \mathrm{J}$ Clin Pharmacol 2: 51-62.

40. Nancy LD, Norma AR, Edgar AM, Blanca RD (2014) Interactions of Chitosan/ Genipin hydrogels during drug delivery: A QSPR approach. Quím Nova 37: 1503-1509.

41. Ghosh G, Naskar MK, Patra A, Chatterjee M (2006) Synthesis and characterization of PVP encapsulated ZnS nanoparticles. Opt Mater 28: 1047-1053.

42. Han TYJ, Worsley MA, Baumann TF, Satcher JH (2011) Synthesis of ZnO coated activated carbon aerogel by simple sol-gel route. J Mater Chem 21 330-333.

43. Sudha M, Rajarajan M (2013) Deactivation of photocatalytically active ZnO nanoparticle by surface capping with poly vinyl pyrrolidone. IOSR J Appl Chem 3: 45-53.

44. Aiman AO, Nadia MA (2009) Improvement of Glibenclamide Bioavailability Using Cyclodextrin Inclusion Complex Dispersed in Polyethylene Glycol. Jordan J Pharm 2: 119-130.

45. Amulyaratna B, Sunit KS (2012) Preparation and Evaluation of GlibenclamideLoaded Biodegradable Nanoparticles. Trop J Pharm Res 11: 345-350.

46. Sharma A, Jain CP (2010) Preparation and characterization of solid dispersions of carvedilol with PVP K30. Res Pharm Sci 5: 49-56.

47. El-kader A, Abu-Abdeen M (2012) Thermal and Mechanical Studies of PVP/2 HEC Blend Films. M.F.H. Aust J Basic Appl Sci 6: 454-462.

48. Sailaja U, Shahin TM (2012) Thermal and Spectroscopic Studies on NizatidinePVP mixture. IOSR J Pharm 2: 17-23.

49. Bartsch SE, Griesser UJ (2004) Physicochemical properties of the binary system glibenclamide and polyethylene glycol 4000 . J Therm Anal Calorim 77: 555-569.

50. Rehder S, Sakmann A, Rades T, Leopold CS (2012) Thermal degradation of amorphous glibenclamide. Eur J Pharm Biopharm 80: 203-208.

51. Yadav PS, Kumar V, Singh UP, Bhat HR, Mazumder B (2013) Physicochemical characterization and in vitro dissolution studies of solid dispersions of ketoprofen with PVP K30 and D-mannitol. Saudi Pharm J 21: 77-84.

52. Bhatt $P$, Patel M (2015) Formulation and Evaluation of Fast Dissolving Film of Rizatriptan Benzoate. Int J Med Pharm Res 1: 58-77.

53. Mona S, Semalty A, Kumar, G (2008) Formulation and characterization of mucoadhesive buccal films of glipizide. Indian J Pharm Sci 70: 43-48.

54. Leuner C, Dressman J (2000) Improving drug solubility for oral delivery using solid dispersions. Eur J Pharm Biopharm 50: 47-60.

55. Broman E, Khoo C, Taylor LS (2001) A comparison of alternative polymer excipients and processing methods for making solid dispersions of a poorly water soluble drug. Int J Pharm 222: 139-151.

56. Crowley MM, Feng Z, Repka MA, Thumma S, Upadhye SB, et al. (2007) Pharmaceutical applications of hot-melt extrusion: Part I. Drug Dev Ind Pharm 33: 909-926.

57. Young CR, Koleng JJ, McGinity JW (2002) Production of spherical pellets by a hot-melt extrusion and spheronization process. Int J Pharm 242: 87-92.

58. Saraiya D, Bolton S (1990) The use of Precirol $^{\circledR}$ to prepare sustained release tablets of theophylline and quinidine gluconate. Drug Dev Ind Pharm 16: 19631969.

59. Mohammed A, Mohamed R, Suryakanth DA, Lakkavalli MSK, Pralhad SP, et al. (2016) Extract of a polyherbal formulation ameliorates experimental nonalcoholic steatohepatitis. J Tradit Complement Med 6: 160-167. 